\title{
Rancang Bangun Sistem Pemantau Keamanan Rumah Dari Tindak Pencurian Berbasis Android Secara Waktu Nyata
}

\author{
Iznih $^{1}$, Kiki Prawiroredjo² \\ 1,2Jurusan Teknik Elektro, \\ Fakultas Teknologi Industri, \\ Universitas Trisakti, Jakarta \\ 1iznih062001904019@std.trisakti.ac.id, ${ }^{2 k i k i . p r a w i r o r e d j o @ t r i s a k t i . a c . i d ~}$
}

\begin{abstract}
Abstrak
Dalam keadaan ekonomi yang sulit di masa pandemi COVID-19 ini, tindak kejahatan menjadi meningkat. Salah satunya yaitu tindak pencurian pada rumah yang ditinggal bekerja oleh penghuninya. Cara yang biasa digunakan untuk mengatasi permasalahan ini yaitu dengan mempekerjakan petugas keamanan atau memasang kamera CCTV. Pada penelitian ini diajukan sebuah sistem pemantauan rumah yang dapat mendeteksi seorang penyusup yang bergerak di depan dan di samping rumah, serta penyusup yang hendak membuka pintu depan dan pintu samping rumah. Sistem dapat memberitahu penghuni rumah dan petugas keamanan jika mendeteksi adanya penyusup melalui aplikasi Android pada smartphone. Sensor Passive Infrared (PIR) dipasang pada area dekat pintu depan dan samping rumah untuk mendeteksi pergerakan orang. Pada pintu depan dan samping dipasang sensor magnetic door switch untuk mendeteksi pembobolan pintu. Data-data sensor diproses oleh WeMos D1 Mini yang terkoneksi WiFi. Ketika status waspada dan bahaya terdeteksi, buzzer di depan rumah akan menyala dan WeMos langsung mengirimkan notifikasi berupa status kondisi rumah ke Android pemilik rumah dan petugas keamanan kompleks perumahan setempat. Berdasarkan hasil pengujian, sistem ini dapat mendeteksi pergerakan manusia di area depan dan samping rumah dengan jarak maksimum 5 meter dari sensor. Berdasarkan hasil pendeteksian magnetic door switch, sistem dapat mengirimkan notifikasi berupa status waspada dan bahaya ke Android pemilik rumah dan petugas keamanan kompleks perumahan setempat dengan waktu pengiriman dari 1 sampai 5 detik. Notifikasi tersebut dapat diterima Android dalam keadaan lock screen maupun dalam keadaan sedang membuka aplikasi lain.
\end{abstract}

Kata kunci: WiFi, WeMos D1 Mini, sensor PIR, sensor magnetic door switch, buzzer, Android

\begin{abstract}
In adverse economic conditions during the COVID-19 pandemic, crime has increased. One of them is the theft of a house left to work by its occupants. The usual way to overcome this problem is by hiring security officers or installing CCTV cameras. This research proposed a home monitoring system that detects an intruder movement in front and beside the house, as well as an intruder who wants to open the front door and side door of the house. The system notifies residents and security personnel if it detects an intruder through the Android application on a smartphone. Passive Infrared (PIR) sensors are installed near the area of the front and side door of the house to detect a human's movement. Magnetic door
\end{abstract}


switches are installed to detect door burglary on the front and side doors. Sensors data is processed by WeMos D1 Mini which is connected to WiFi. When warning and danger statuses are detected, a buzzer turns on and WeMos immediately sends notifications of the house conditions to homeowner's and local security officer's smartphone. Based on the test results, the sensor detects human's movements in front of or on the side area of the house until 5 meters. Notifications about warning and danger status are sent to the homeowner's and the local security officer's smartphone in 1 to 5 seconds. These notifications can be received by the smartphone in a lock screen condition or when running other applications.

Keywords: WiFi, WeMos D1 Mini, PIR sensor, magnetic door switch sensor, buzzer, Android

\section{Pendahuluan}

Di masa pandemi COVID-19 bukan hanya kesehatan yang menjadi permasalahan masyarakat, akan tetapi masyarakat juga dihadapkan pada masalah ekonomi. Di tengah pandemi ini, pemerintah menghimbau masyarakat untuk tetap berada di rumah, sehingga dapat memutus matarantai penyebaran COVID-19. Banyak orang mengikuti himbauan tersebut, akan tetapi beberapa orang juga tidak menghiraukan dikarenakan faktor ekonomi yang mengharuskan mereka untuk tetap mencari nafkah di luar rumah. Dampak dari pandemi ini, banyak orang yang terkena Pemutusan Hubungan Kerja (PHK) dan dirumahkan sementara. Di kondisi ekonomi yang sulit seperti ini membuat tindak kriminalitas menjadi meningkat, salah satunya yaitu tindak pencurian pada rumah yang ditinggal bekerja oleh penghuninya.

Kapolda Metro Jaya mengungkapkan bahwa tindak kriminalitas di wilayah Jabodetabek meningkat sebesar 10\% selama pandemi COVID-19 sejak Maret hingga April 2020 yang mana salah satu tindak kriminalitas yang terjadi adalah pencurian pada rumah kosong [1]. Kasatreskrim Polrestabes Bandung memaparkan pencurian pada rumah kosong mendominasi angka kriminalitas sepanjang 2020 sebanyak 3,436 kejadian [2]. Untuk mencegah dan mengatasi tindak pencurian ini, umumnya pemilik rumah mempekerjakan petugas keamanan pribadi atau memasang kamera Closed Circuit Television (CCTV)). Akan tetapi, cara ini membutuhkan biaya yang cukup besar. Pada penelitian ini diusulkan sebuah sistem pemantauan keamanan rumah sebagai pendeteksi dan peringatan dini yang efektif serta efisien yaitu dengan memasang sensor-sensor pada bagian depan, samping dan pintu rumah serta mengirimkan notifikasi ke pemilik rumah dan penjaga keamanan kompleks melalui aplikasi Android pada smartphone bila sensor mendeteksi tindakan pencurian.

Sistem yang dibuat di sini menggunakan sensor PIR dan magnetic door switch serta mikrokontroler sebagai pengolah sinyal dari sensor yang terhubung ke jaringan internet secara waktu nyata (real-time). Sistem ini dirancang agar mampu mendeteksi status waspada yaitu bila sensor mendeteksi pergerakan seorang penyusup atau bahaya yaitu bila sensor mendeteksi adanya pembobolan pintu rumah. Ketika salah satu dari status tersebut terdeteksi, sistem ini akan langsung mengirimkan notifikasi dan peringatan secara otomatis ke smartphone pemilik rumah dan petugas keamanan kompleks perumahan setempat di mana mereka tidak perlu membuka terlebih dahulu aplikasi tersebut. Adapun notifikasi dan peringatannya berupa pesan yang berisikan status waspada dan bahaya yang disertai alamat rumah. Sistem ini dilengkapi getaran dan alarm pada smartphone yang akan aktif secara otomatis bila notifikasi dikirimkan. Pengembangan sistem ini bertujuan agar rumah terhindar dari tindak pencurian, 
sehingga pemilik rumah tidak lagi merasa khawatir ketika meninggalkan rumahnya dalam kondisi kosong atau tidak berpenghuni.

\section{Metode Penelitian}

Sistem pemantauan keamanan rumah seperti ini sudah pernah dibuat oleh beberapa mahasiswa teknik di seluruh dunia dengan menggunakan metode yang berbeda-beda. Rajesh Khana dan Uus Usnul membuat sistem keamanan rumah menggunakan Arduino Uno dan ESP8266 [3]. Sistem ini menggunakan sensor PIR dan solenoid door lock untuk keamanan rumah yang dapat mengirimkan notifikasi berupa e-mail ke pemilik rumah. Akan tetapi, sistem ini tidak dapat memberikan notifikasi berupa alamat rumah, getaran, dan alarm secara otomatis ke Android pemilik rumah dan petugas keamanan kompleks perumahan setempat.

Penelitian lain ada yang menggunakan kamera CCTV. Dedi Setiawan, dan Joni Eka membuat sistem keamanan rumah dengan menggunakan Arduino Uno yang dikoneksikan dengan CCTV dan sensor PIR [4]. Sistem ini dapat memantau keamanan rumah melalui aplikasi Telegram Messenger di mana pemilik rumah dapat melihat foto yang ditangkap oleh CCTV. Akan tetapi biaya pembuatan sistem ini tergolong mahal karena menggunakan CCTV. Selain itu, sistem ini mengharuskan pemilik rumah membuka terlebih dahulu aplikasi Telegram Messenger dan mengirimkan suatu instruksi pada aplikasi tersebut untuk dapat melihat hasil foto yang ditangkap oleh CCTV. Sistem ini juga belum dilengkapi notifikasi otomatis ketika Android dalam kondisi standby atau lock screen.

Jaja Irianto dan Winarno juga pernah merancang dan membangun sistem keamanan rumah dengan menggunakan sensor PIR serta Raspberry PI. Mereka merancang sistem ini dengan konsep Internet of Things (IoT) di mana sistem terintegrasi dengan aplikasi Telegram Messenger [5]. Sistem ini juga menggunakan kamera CCTV sebagai media untuk menangkap kondisi ruangan. Sama seperti penelitian sebelumnya, pemilik rumah diharuskan memberikan suatu instruksi untuk dapat melihat foto yang ditangkap oleh CCTV. Selain itu sistem ini juga belum memiliki notifikasi serta peringatan dini ketika rumah beresiko bahaya.

Sistem keamanan rumah berbasis IoT di mana kondisi rumah dapat dipantau dengan menggunakan aplikasi Telegram Messenger juga pernah dibuat oleh Muchamad Sobri Sungkar [6]. Sistem ini menggunakan WeMos sebagai mikrokontroler dan PIR sensor yang berfungsi untuk mendeteksi pergerakan orang pada area rumah. Sistem ini dapat mengirimkan pesan ke aplikasi Telegram Messenger. Namun sistem ini hanya mampu mengirimkan pesan notifikasi ketika aplikasi tersebut dalam keadaan standby. Sehingga ketika Android pemilik rumah dalam keadaan lock screen, sistem ini akan kesulitan untuk mengirimkan pesan notifikasi tersebut.

Eki Ahmad Zaki Hamidi dan Mufido Ridlo Effendi membuat prototipe sistem keamanan rumah berbasis web dan Short Message Service (SMS) gateway [7]. Sistem ini menggunakan CCTV dan sensor PIR. Ketika sistem mendeteksi suatu pergerakan yang mencurigakan, maka sistem akan mengirimkan notifikasi berupa SMS ke pemilik rumah. Hal ini terbilang cukup praktis, akan tetapi kurang efektif karena beberapa providers kartu seluler sering mengirimkan SMS berupa promosi produk mereka sehingga beresiko membuat notifikasi SMS sistem tenggelam ketika sampai ke handphone pemilik rumah. 
Sedangkan dengan menggunakan web pemilik rumah diwajibkan membuka terlebih dahulu web pada browser.

Berdasarkan hal tersebut dilakukan sebuah penelitian sistem keamanan rumah yang lebih praktis sehingga dapat memudahkan pemilik rumah untuk memantau kondisi rumahnya secara waktu nyata. Metode penelitian ini terdiri dari beberapa tahap yaitu; perancangan sistem yang dapat memantau pergerakan orang di area sekitar rumah serta memantau pembobolan pintu rumah, perancangan perangkat keras, perancangan perangkat lunak agar pesan notifikasi dapat diterima ketika Android dalam keadaan lock screen maupun sedang membuka aplikasi lain, pembuatan serta pengujian sistem. Komponen sistem yang digunakan pada penelitian ini terdiri dari perangkat keras yaitu WeMos D1 Mini, sensor PIR HC-SR051, sensor magnetic door switch MC-38, dan buzzer. Perangkat lunak yang digunakan yaitu software Arduino IDE, Ubidots, dan aplikasi Android.

\subsection{Diagram Blok Sistem}

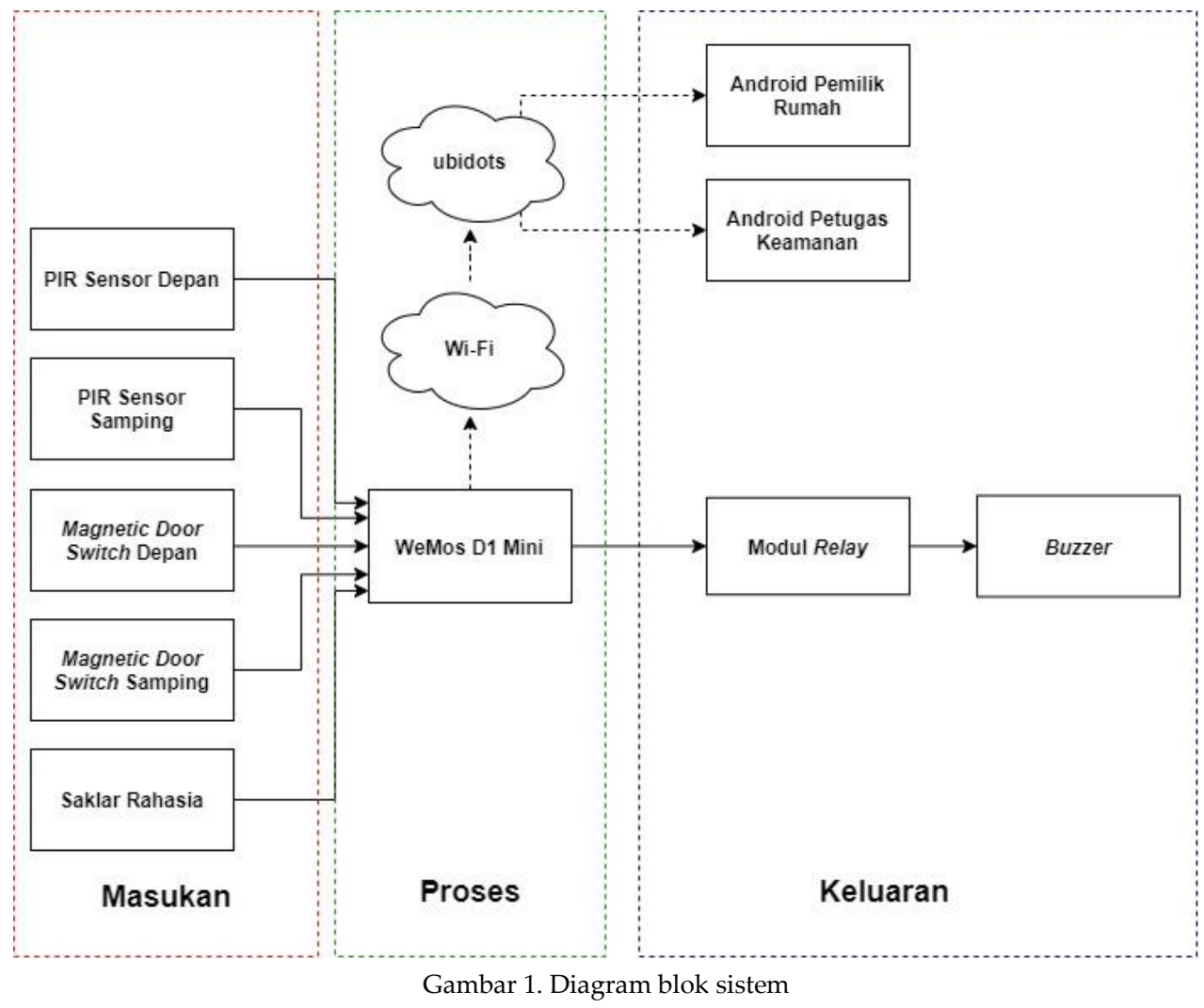

Bagian input dari diagram blok sistem pada Gambar 1 terdapat dua buah PIR sensor, dua buah magnetic door switch, dan sebuah saklar rahasia. Data input dari sensor-sensor tersebut akan diproses oleh kontroler yaitu WeMos yang terkoneksi dengan WiFi. Keluaran WeMos akan mengaktifkan buzzer sebagai indikator bunyi serta mengirimkan notifikasi secara wireless ke smartphone pemilik rumah dan petugas keamanan setempat. Sensor PIR mampu mendeteksi sinar inframerah dengan panjang gelombang $8-14 \mu \mathrm{m}$ yang sesuai dengan karakteristik pancaran sinar inframerah pada tubuh manusia, sehingga sensor PIR hanya mendeteksi pergerakan manusia di area depan dan samping 
rumah. Magnetic door switch berfungsi untuk mendeteksi pembobolan pintu depan atau samping rumah. Saklar rahasia sebagai input digunakan untuk mereset sistem.

Untuk mendeteksi pergerakan seorang penyusup, sistem ini menggunakan sensor PIR HC-SR501 yang dipasang pada area dekat pintu depan dan samping rumah. Sensor ini memiliki area jangkauan sampai dengan kurang lebih 7 meter. Data keluaran dari sensor PIR ini berupa data digital. Ketika sensor ini mendeteksi adanya pergerakan orang, maka sistem akan langsung menyalakan buzzer dan mengirimkan notifikasi berupa status 'WASPADA' pada smartphone pemilik rumah dan petugas keamanan kompleks setempat. Magnetic door switch MC-38 yang dipasang pada pintu depan dan samping rumah berfungsi untuk mendeteksi dibobolnya pintu rumah oleh pencuri. Ketika pintu rumah dalam keadaan terbuka atau dibobol oleh pencuri, buzzer akan menyala dan sistem langsung mengirimkan notifikasi berupa status 'BAHAYA' pada smartphone pemilik rumah dan petugas keamanan kompleks setempat.

Notifikasi dan peringatan dini pada sistem ini dirancang agar dapat diterima oleh pemilik rumah ataupun petugas keamanan ketika smartphone dalam keadaan standby, sedang membuka aplikasi lain, maupun lock screen. Hal ini bertujuan agar pemilik rumah dan petugas keamanan menjadi lebih cepat dan tanggap untuk mengetahui kondisi rumah tanpa harus membuka terlebih dahulu atau tanpa perlu sesekali mengecek aplikasi Android. Ketika sistem ini mendeteksi status 'WASPADA' atau 'BAHAYA' pada rumah, notifikasi berupa lokasi di mana status tersebut sedang terjadi (depan atau samping rumah), alamat rumah dan peringatan dini berupa alarm serta getaran langsung dikirimkan ke smartphone pemilik rumah serta petugas keamanan kompleks perumahan setempat.

\subsection{Perancangan Perangkat Keras}

Gambar 2 adalah skema rangkain sistem di mana pada bagian masukan terdapat 2 buah sensor PIR HC-SR501 yang dihubungkan dengan pin D7 dan D8 pada WeMos yang berfungsi untuk mendeteksi pergerakan manusia di sekitar area depan dan samping rumah. Terdapat juga 2 buah sensor magnetic door switch MC-38 yang dipasang dengan kondisi Normally Closed pada ground dan dihubungkan dengan pin D1 dan D2 WeMos yang berfungsi untuk mendeteksi pembobolan pintu depan atau samping rumah. Selain itu, terdapat juga sebuah saklar yang dipasang secara Normally Closed pada sumber tegangan 5V. Pada bagian proses, sistem ini menggunakan mikrokontroler WeMos yang dihubungkan ke WiFi. Mikrokontroler ini berfungsi untuk mengolah semua data sensor sehingga dapat mengaktifkan kanal modul relay yang kemudian menghasilkan keluaran berupa notifikasi buzzer. 


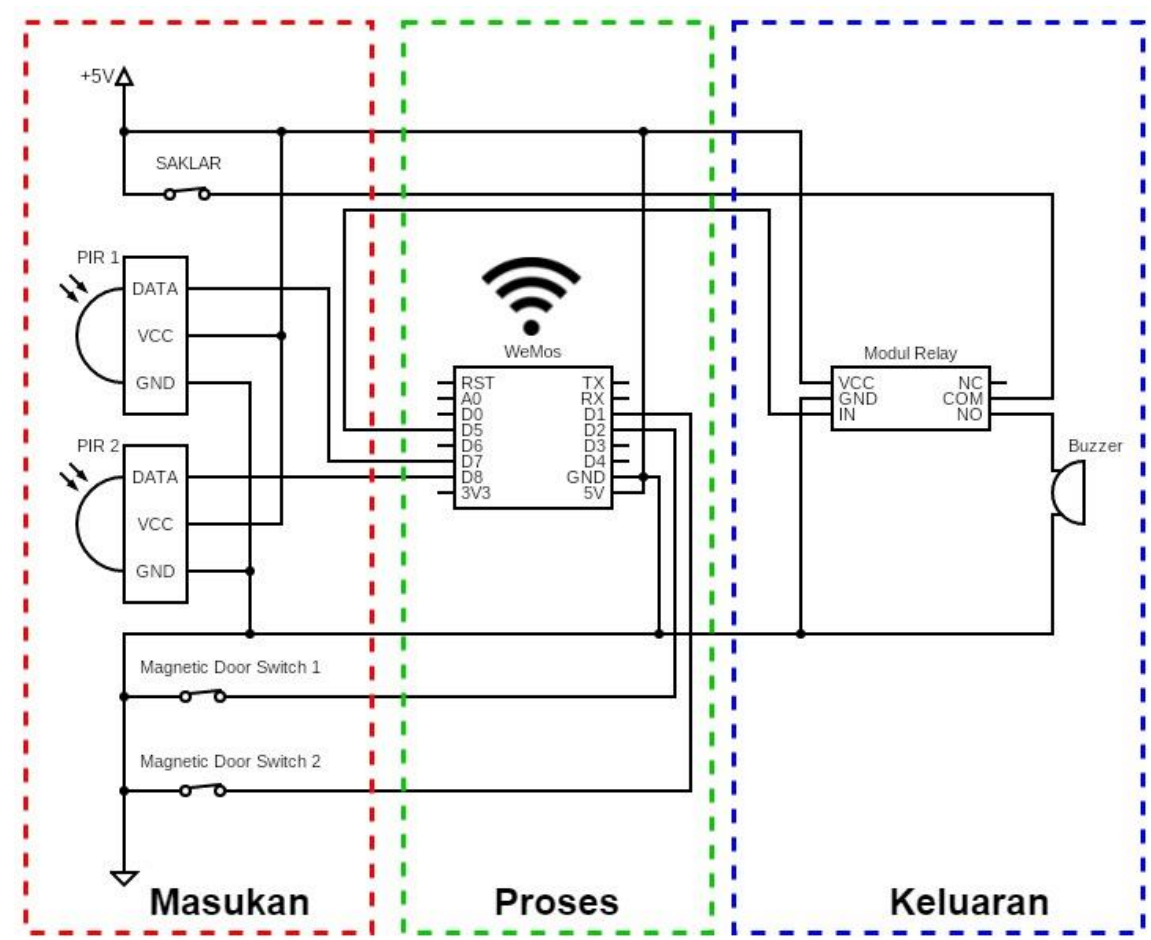

Gambar 2. Skema rangkaian sistem

\subsection{Perancangan Perangkat Lunak}

Pada Gambar 3 diperlihatkan diagram alir perangkat lunak sistem. Pertama-tama WeMos akan dikoneksikan ke WiFi. Setelah WeMos sudah dipastikan terkoneksi dengan WiFi, WeMos akan mulai mendeteksi pergerakan manusia di sekitar area depan dan samping rumah dengan menggunakan sensor PIR. Ketika ada pergerakan manusia yang terdeteksi, WeMos akan langsung mengaktifkan buzzer sebagai indikator bunyi serta mengirimkan notifikasi berupa status waspada, alamat rumah, dan alarm yang disertai getaran pada smartphone pemilik rumah dan petugas keamanan kompleks perumahan setempat. Magnetic door switch yang dipasang pada pintu depan dan samping rumah berfungsi untuk mendeteksi pembobolan pintu. Ketika switch ini mendeteksi adanya pembobolan pintu rumah, WeMos akan langsung mengaktifkan buzzer sebagai indikator bunyi serta mengirimkan notifikasi berupa status bahaya, alamat rumah, dan alarm yang disertai getaran pada smartphone pemilik rumah dan petugas keamanan kompleks perumahan setempat. Gambar 4 adalah contoh dari tampilan aplikasi Android yang berisikan status rumah, sedangkan Gambar 5 adalah contoh notifikasi yang dikirimkan sistem ke Android. Untuk me-reset sistem, digunakan sebuah saklar rahasia di mana ketika saklar ini diaktifkan, maka buzzer yang mulanya berbunyi akan menjadi padam. 


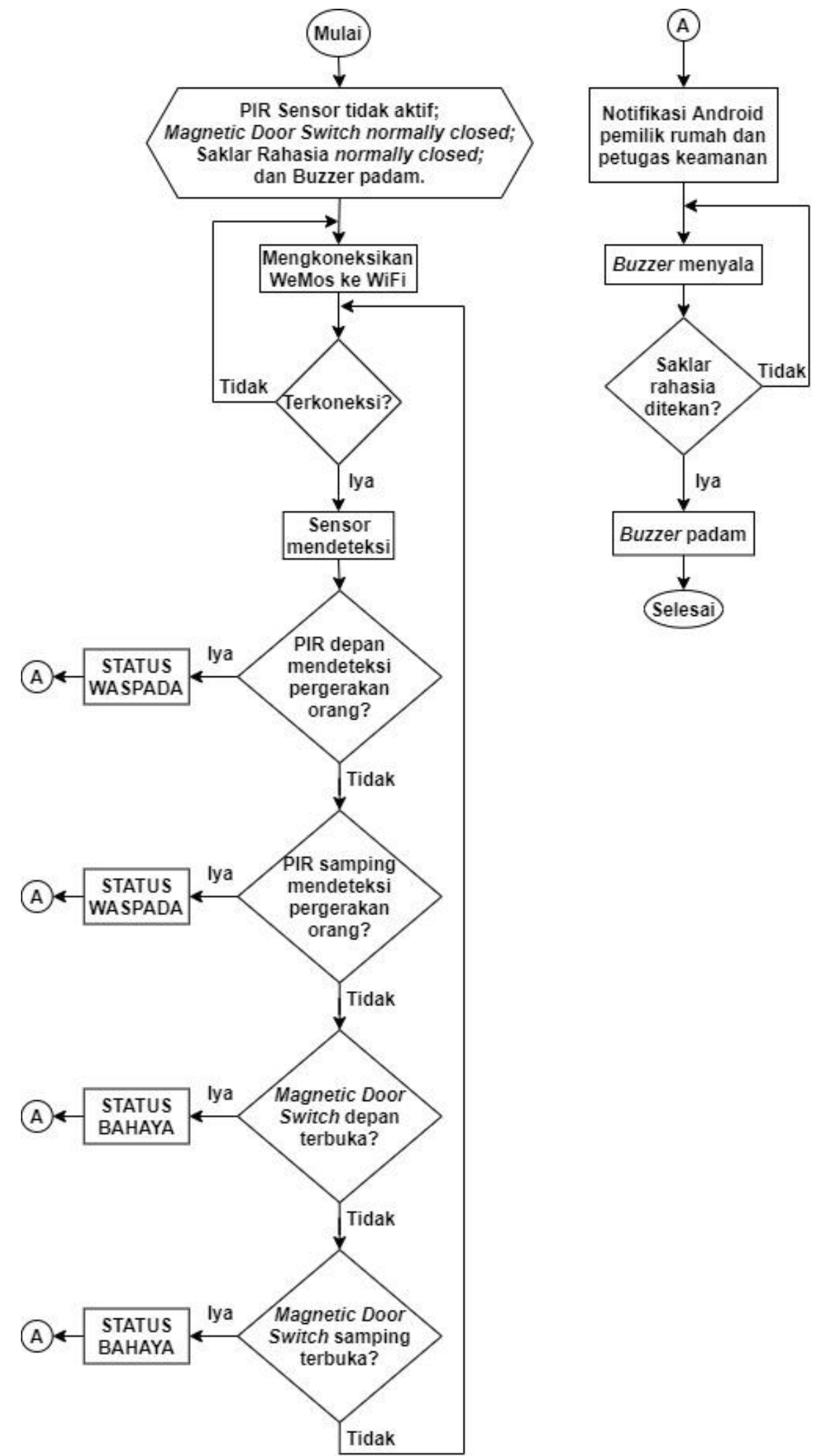

Gambar 3. Diagram alir perangkat lunak 

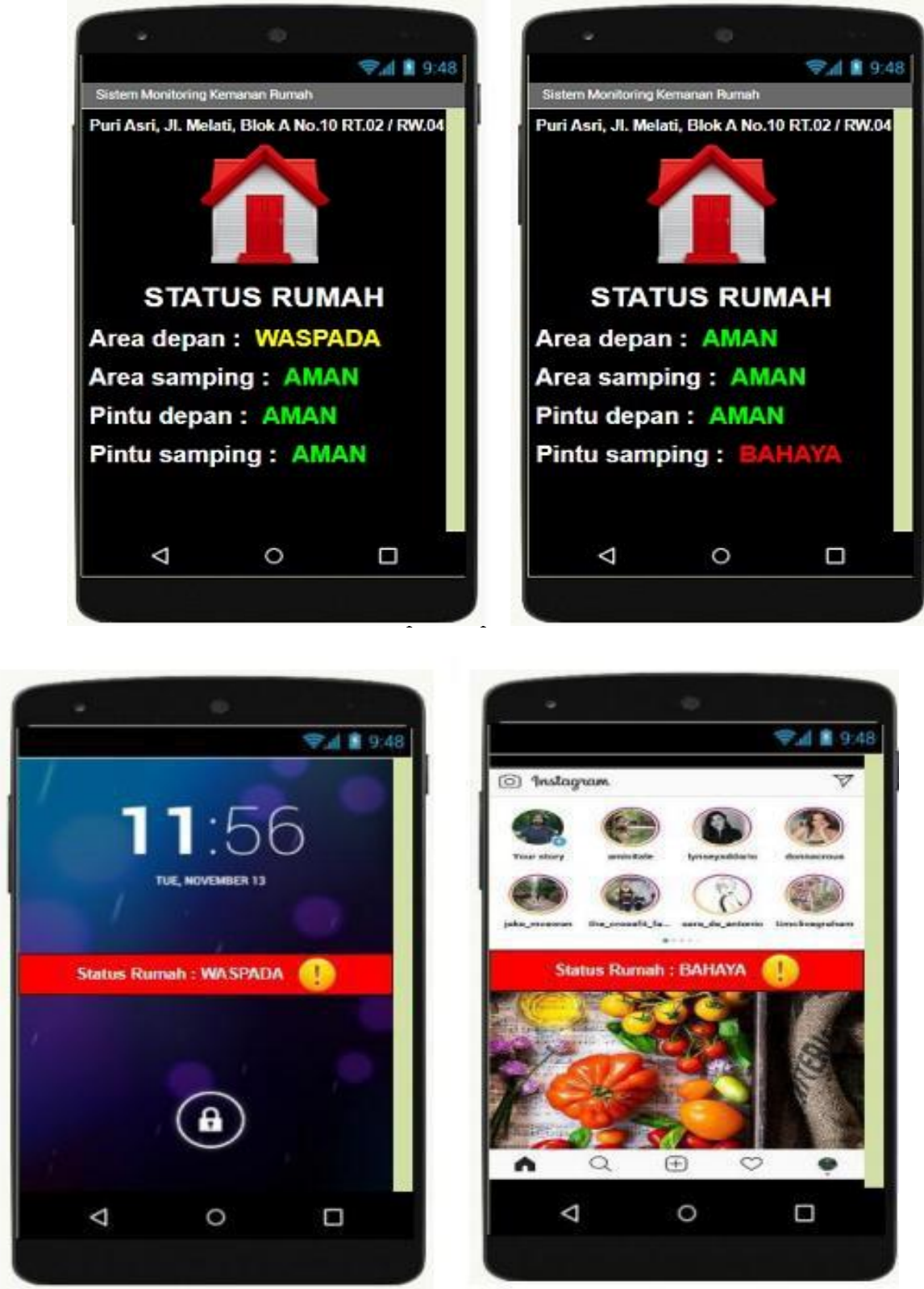

Gambar 5. Tampilan pop-up notifikasi Android

\section{Hasil dan Pembahasan}

\subsection{Pembuatan Perangkat Keras}

Sistem ini terdiri dari 2 bagian utama yaitu; bagian depan rumah dan bagian samping rumah. Model pada sistem ini berukuran $40 \times 35 \times 15 \mathrm{~cm}$ untuk panjang, lebar, dan tinggi. Gambar 6 adalah bentuk fisik dari sistem di mana terdapat sensor PIR HC-SR501 pada area depan dan samping yang berfungsi untuk mendeteksi pergerakan manusia disekitar area tersebut. Selain itu terdapat juga magnetic switch MC-38 pada area depan dan samping yang berfungsi untuk mendeteksi pembobolan pintu depan dan samping. 


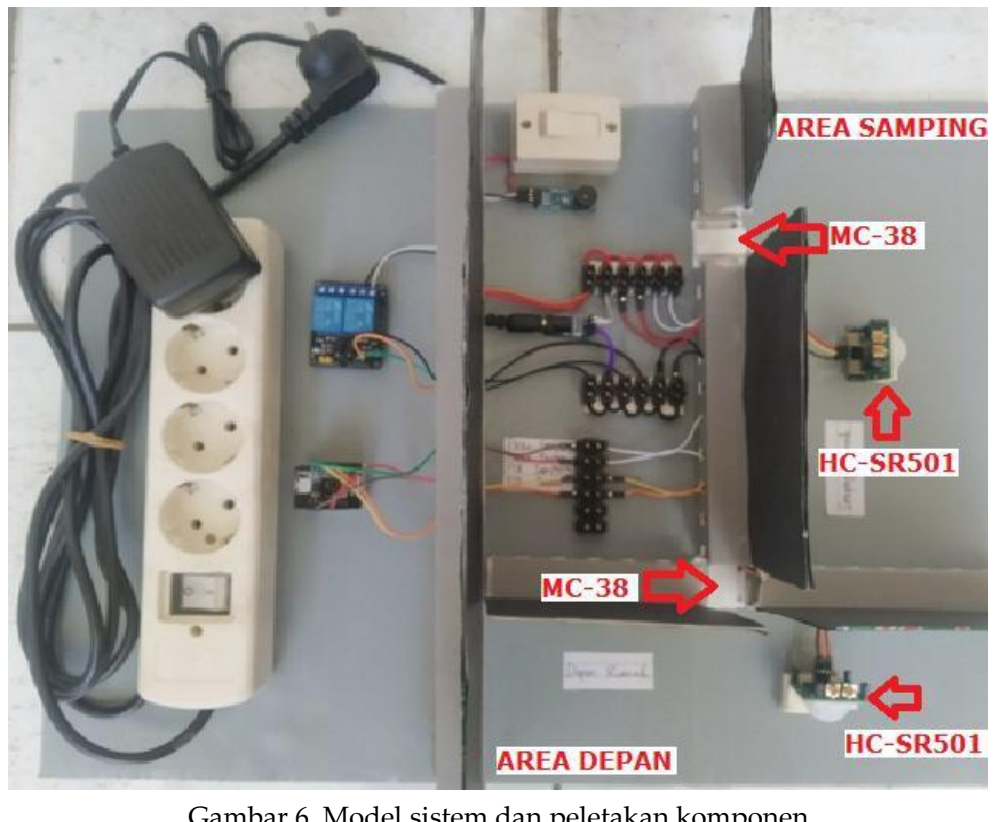

\subsection{Pengujian Konektivitas Sistem}

Sistem ini menggunakan WeMos D1 Mini sebagai mikrokontroler dimana modul ini berfungsi untuk proyek berkonsep IoT. Gambar WeMos D1 Mini dapat dilihat pada Gambar 7. Board ini sudah dilengkapi dengan modul WiFi yaitu ESP8266 sehingga dapat beroperasi stand-alone serta dapat mentrasfer data secara wireless [8].

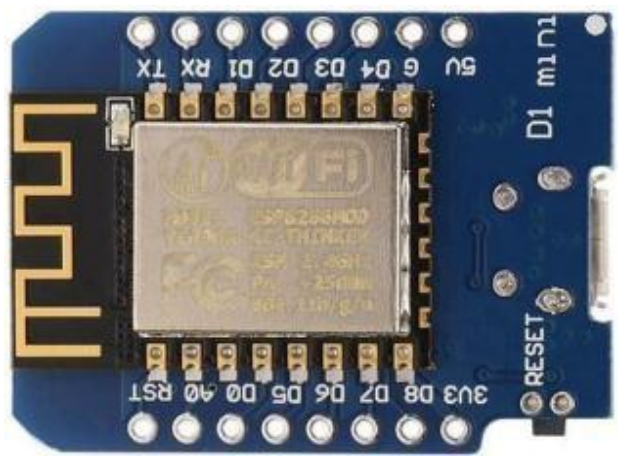

Gambar 7. WeMos D1 Mini

Pengujian konektivitas bertujuan untuk mengetahui apakah WeMos sudah terhubung dengan jaringan internet sehingga dapat terintegrasi dengan Ubidots dan aplikasi Android. Cara menguji konektivitas dilakukan dengan 3 metode seperti dijelaskan berikut ini.

Metode pertama dengan menggunakan serial monitor pada Arduino IDE. Software ini menghasilkan sebuah file berformat hex untuk memprogram WeMos. Metode ini bertujuan untuk mengetahui apakah WeMos sudah atau belum terhubung ke WiFi. Caranya dengan meng-upload program yang sudah dibuat ke WeMos, lalu membuka dan mengamati tampilan serial monitor pada Arduino IDE. Gambar 8 adalah tampilan serial monitor di mana sistem terhubung ke WiFi. 


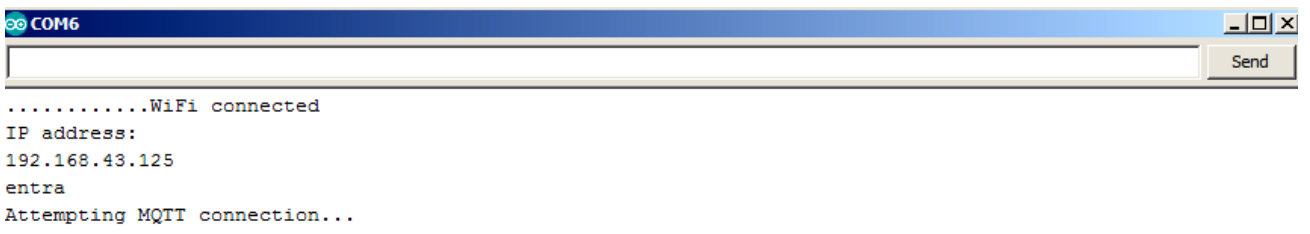

Gambar 8. Serial monitor WeMos terhubung ke WiFi

Metode kedua yang dilakukan yaitu mengamati tampilan pada dashboard Ubidots. Metode ini bertujuan untuk mengetahui apakah WeMos sudah atau belum terintegrasi secara real-time pada Ubidots. Caranya dengan membuka tampilan dashboard Ubidots serta mengamati header dan indikator sensor pada dashboard tersebut. Gambar 9 adalah tampilan dashboard Ubidots di mana WeMos sudah terintegrasi secara real-time.

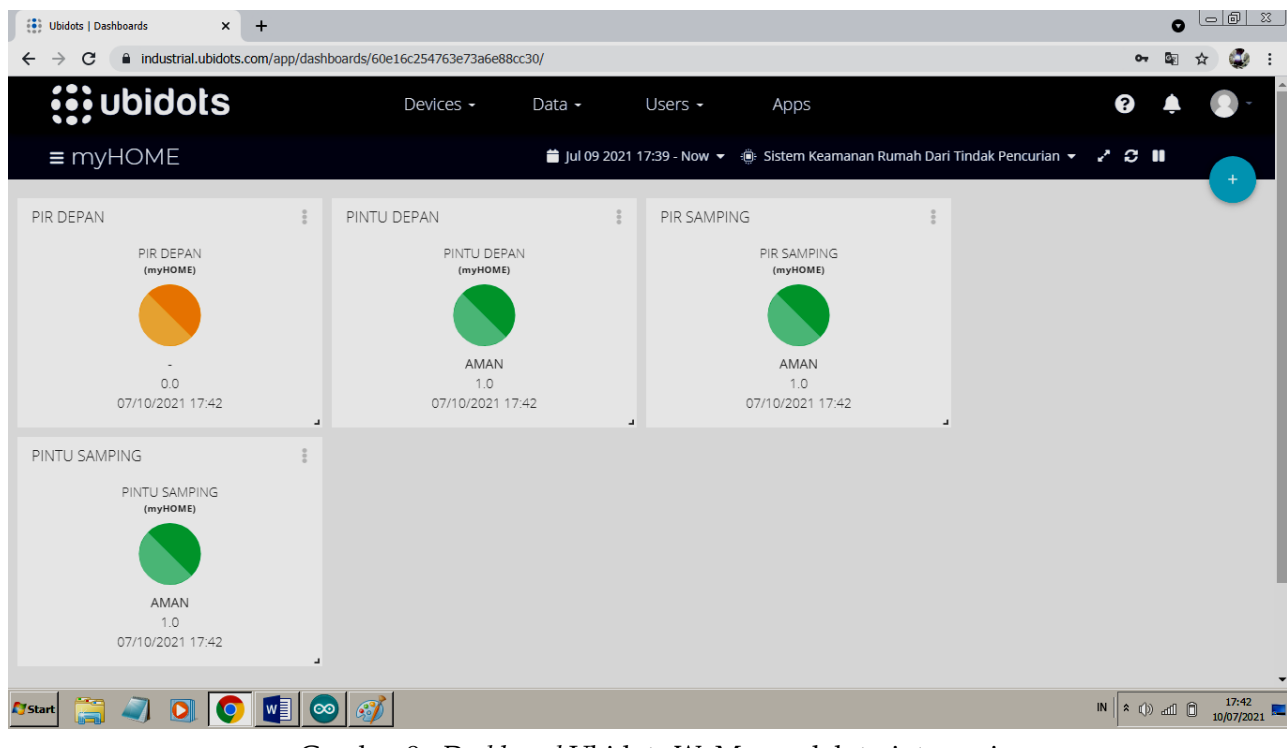

Gambar 9. Dashboard Ubidots WeMos sudah terintegrasi

Metode ketiga yang dilakukan yaitu dengan mengamati tampilan pada aplikasi Android. Metode ini bertujuan untuk mengetahui apakah dashboard Ubidots sudah atau belum terintegrasi dengan aplikasi Android secara real-time. Caranya dengan membuka dan mengamati tampilan aplikasi Android. Gambar 10 adalah aplikasi Android yang sudah terintegrasi dengan dashboard Ubidots secara real-time sedangkan Gambar 11 adalah aplikasi Android yang tidak terintegrasi. Adapun hasil pengujian konektivitas sistem dapat dilihat pada Tabel 1. 


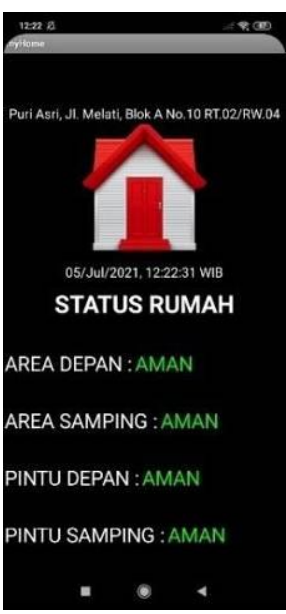

Gambar 10. Aplikasi Android terhubung ke Dashboard Ubidots

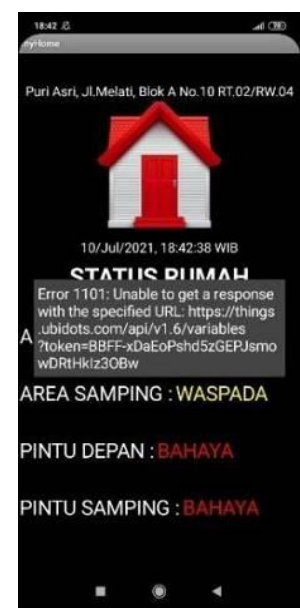

Gambar 11. Aplikasi Android tidak terhubung ke Dashboard Ubidots

Tabel 1. Hasil pengujian konektivitas WeMos

\begin{tabular}{|c|c|c|c|c|c|c|}
\hline No & Metode & Lokasi & Cuaca & Provider & $\begin{array}{c}\text { Kecepatan } \\
{[\text { Mpbs }]}\end{array}$ & Hasil \\
\hline 1 & Serial Monitor Arduino IDE & $\begin{array}{c}\text { Jakarta, Duren } \\
\text { Sawit }\end{array}$ & Cerah & T-Sel & 17.4 & Terhubung \\
\hline 2 & Dashboard ubidots & $\begin{array}{c}\text { Jakarta, Duren } \\
\text { Sawit }\end{array}$ & Cerah & T-Sel & 17.4 & Terhubung \\
\hline 3 & Aplikasi Android & $\begin{array}{c}\text { Jakarta, Duren } \\
\text { Sawit }\end{array}$ & Cerah & T-Sel & 17.4 & Terhubung \\
\hline
\end{tabular}

\subsection{Pengujian Status Waspada}

Pengujian ini dilakukan dengan menggunakan sensor PIR HC-SR501. Sensor ini dipasang secara horizontal di dekat pintu rumah pada area depan dan samping. Hal ini bertujuan untuk mendapatkan respon yang cepat dari sensor. Karena jika sensor dipasang secara vertikal pada plafon rumah, sensor ini menjadi kurang responsif yang disebabkan oleh sudut jangkauan sensor yang terbatas yaitu $110^{\circ}$ [9]. Gambar HC-SR501 dapat dilihat pada Gambar 12.

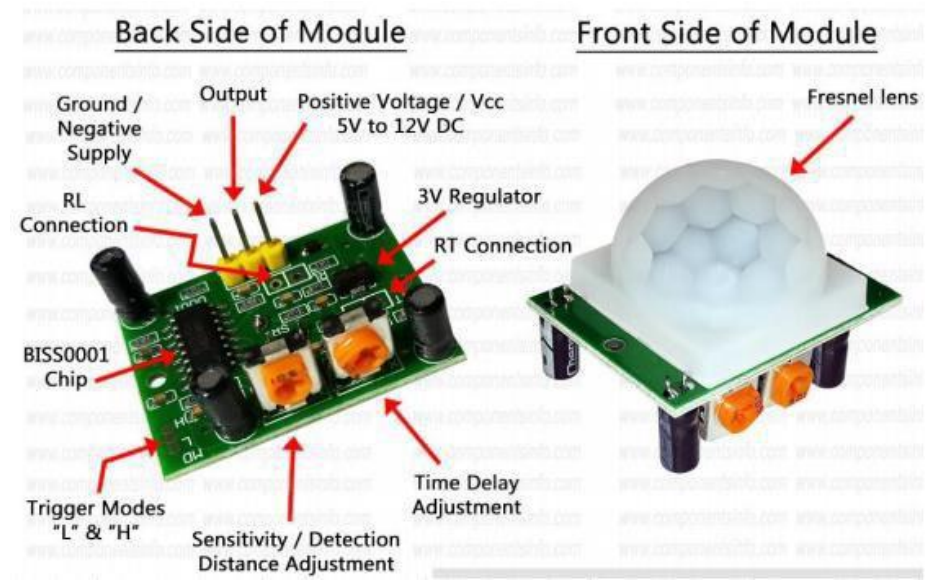

Gambar 12. PIR HC-SR501 
Pengujian ini bertujuan untuk mengetahui jarak maksimum dari pergerakan manusia yang dapat dideteksi oleh PIR sensor HC-SR501 dan mengetahui berapa lama waktu respon dari sistem untuk mengirimkan status waspada pada Aplikasi Android. Adapun metode pengujian yang dilakukan adalah dengan mencoba mengaktifkan secara manual sensor ini pada beberapa jarak tertentu sampai jarak maksimal di mana sensor ini sudah tidak bisa mendeteksi. Tabel 2 adalah data hasil pengujian PIR sensor HC-SR501 pada area depan rumah dan Tabel 3 adalah data hasil pengujian PIR sensor HC-SR501 pada area samping rumah.

Tabel 2 Data hasil deteksi PIR sensor HC-SR501 area depan rumah

\begin{tabular}{|c|c|c|c|c|c|}
\hline No & Jarak & HC-SR501 & Aplikasi Android & Delay & Alarm \\
\hline 1 & $0,5 \mathrm{~m}$ & Aktif & WASPADA & 2 detik & Aktif \\
\hline 2 & $1 \mathrm{~m}$ & Aktif & WASPADA & 2 detik & Aktif \\
\hline 3 & $1,5 \mathrm{~m}$ & Aktif & WASPADA & 2 detik & Aktif \\
\hline 4 & $2 \mathrm{~m}$ & Aktif & WASPADA & 2 detik & Aktif \\
\hline 5 & $2,5 \mathrm{~m}$ & Aktif & WASPADA & 3 detik & Aktif \\
\hline 6 & $3 \mathrm{~m}$ & Aktif & WASPADA & 3 detik & Aktif \\
\hline 7 & $3,5 \mathrm{~m}$ & Aktif & WASPADA & 3 detik & Aktif \\
\hline 8 & $4 \mathrm{~m}$ & Aktif & WASPADA & 4 detik & Aktif \\
\hline 9 & $4,5 \mathrm{~m}$ & Aktif & WASPADA & 4 detik & Aktif \\
\hline 10 & $5 \mathrm{~m}$ & Aktif & WASPADA & 4 detik & Aktif \\
\hline 11 & $5,1 \mathrm{~m}$ & Tidak Aktif & AMAN & - & Tidak Aktif \\
\hline
\end{tabular}

Dari hasil Tabel 2 sensor PIR HC-SR501 area depan rumah dapat mendeteksi adanya pergerakan manusia sampai jarak maksimum sejauh 5 meter. Sensor ini membutuhkan waktu delay 2 sampai 4 detik untuk dapat mendeteksi adanya pergerakan manusia. Waktu delay ini dipengaruhi oleh kondisi jaringan internet yang digunakan.

Tabel 3. Data hasil deteksi PIR sensor HC-SR501 area samping rumah

\begin{tabular}{|c|c|c|c|c|c|}
\hline No & Jarak & HC-SR501 & Aplikasi Android & Delay & Alarm \\
\hline 1 & $0,5 \mathrm{~m}$ & Aktif & WASPADA & 2 detik & Aktif \\
\hline 2 & $1 \mathrm{~m}$ & Aktif & WASPADA & 2 detik & Aktif \\
\hline 3 & $1,5 \mathrm{~m}$ & Aktif & WASPADA & 2 detik & Aktif \\
\hline 4 & $2 \mathrm{~m}$ & Aktif & WASPADA & 2 detik & Aktif \\
\hline 5 & $2,5 \mathrm{~m}$ & Aktif & WASPADA & 3 detik & Aktif \\
\hline 6 & $3 \mathrm{~m}$ & Aktif & WASPADA & 3 detik & Aktif \\
\hline 7 & $3,5 \mathrm{~m}$ & Aktif & WASPADA & 3 detik & Aktif \\
\hline 8 & $4 \mathrm{~m}$ & Aktif & WASPADA & 4 detik & Aktif \\
\hline 9 & $4,5 \mathrm{~m}$ & Aktif & WASPADA & 4 detik & Aktif \\
\hline 10 & $5 \mathrm{~m}$ & Aktif & WASPADA & 4 detik & Aktif \\
\hline 11 & $5,1 \mathrm{~m}$ & Tidak Aktif & AMAN & - & Tidak Aktif \\
\hline
\end{tabular}

Dari hasil Tabel 3 sensor PIR HC-SR501 area samping rumah dapat mendeteksi adanya pergerakan manusia sampai jarak maksimum sejauh 5 meter. Selain itu sensor ini membutuhkan waktu delay 2 sampai 4 detik untuk dapat mendeteksi adanya pergerakan manusia.Waktu delay yang bervariasi ini dipengaruhi oleh kondisi jaringan internet yang digunakan saat itu. 


\subsection{Pengujian Status Bahaya}

Pengujian ini dilakukan dengan menggunakan sensor magnetic door switch MC-38 yang biasanya dipasangkan pada pintu dan jendela seperti pada Gambar 13. Sensor ini beroperasi dengan menggunakan gelombang elektromagnetik sebagai pemicunya [10]. Ketika magnet sensor ini didekatkan, maka saklar akan terhubung, sedangkan saat magnet tidak ada saklar akan terputus.

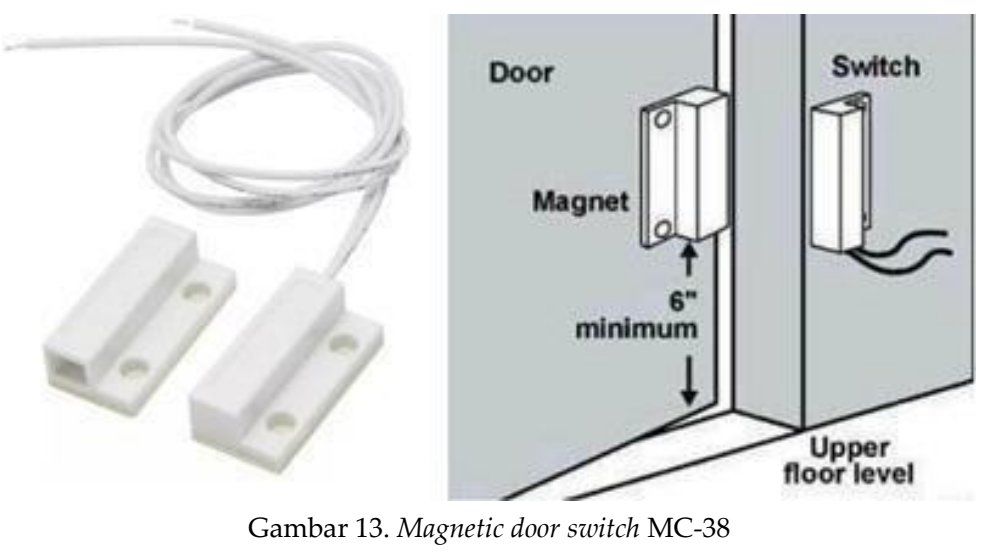

Metode pengujian ini dengan membuat switch MC-38 yang semula dalam kondisi tertutup menjadi kondisi terbuka. Tabel 4 adalah data hasil pengujian Magnetic door switch MC-38 pada pintu depan rumah dan Tabel 5 adalah data hasil pengujian Magnetic door switch MC-38 pada pintu samping rumah.

Tabel 4. Data hasil deteksi MC-38 pintu depan rumah

\begin{tabular}{|c|c|c|c|c|}
\hline No & MC-38 & Aplikasi Android & Delay & Alarm \\
\hline 1 & Aktif & BAHAYA & 1 detik & Aktif \\
\hline 2 & Aktif & BAHAYA & 1 detik & Aktif \\
\hline 3 & Aktif & BAHAYA & 1 detik & Aktif \\
\hline 4 & Aktif & BAHAYA & 2 detik & Aktif \\
\hline 5 & Aktif & BAHAYA & 1 detik & Aktif \\
\hline 6 & Aktif & BAHAYA & 1 detik & Aktif \\
\hline 7 & Aktif & BAHAYA & 3 detik & Aktif \\
\hline 8 & Aktif & BAHAYA & 1 detik & Aktif \\
\hline 9 & Aktif & BAHAYA & 2 detik & Aktif \\
\hline 10 & Aktif & BAHAYA & 1 detik & Aktif \\
\hline
\end{tabular}

Dari Tabel 4 dapat dilihat, switch MC-38 membutuhkan waktu delay 1 sampai 3 detik untuk dapat mendeteksi adanya pembobolan pintu depan rumah. Waktu delay yang ini dipengaruhi oleh kondisi jaringan internet yang digunakan saat itu.

Dari hasil Tabel 5, switch MC-38 membutuhkan waktu delay 1 sampai 2 detik untuk dapat mendeteksi adanya pembobolan pintu samping rumah. Waktu delay dipengaruhi oleh kondisi jaringan internet yang digunakan. 
Tabel 5. Data Hasil deteksi MC-38 pintu samping rumah

\begin{tabular}{|c|c|c|c|c|}
\hline No & MC-38 & Aplikasi Android & Delay & Alarm \\
\hline 1 & Aktif & BAHAYA & 1 detik & Aktif \\
\hline 2 & Aktif & BAHAYA & 1 detik & Aktif \\
\hline 3 & Aktif & BAHAYA & 1 detik & Aktif \\
\hline 4 & Aktif & BAHAYA & 2 detik & Aktif \\
\hline 5 & Aktif & BAHAYA & 2 detik & Aktif \\
\hline 6 & Aktif & BAHAYA & 2 detik & Aktif \\
\hline 7 & Aktif & BAHAYA & 1 detik & Aktif \\
\hline 8 & Aktif & BAHAYA & 1 detik & Aktif \\
\hline 9 & Aktif & BAHAYA & 1 detik & Aktif \\
\hline 10 & Aktif & BAHAYA & 2 detik & Aktif \\
\hline
\end{tabular}

\subsection{Pengujian Pop-up Notifikasi}

Pengujian ini dilakukan dengan mengaktifkan status waspada dan bahaya ketika kondisi smartphone pada keadaan lock screen dan sedang membuka aplikasi lain. Caranya dengan mengaktifkan sensor yang ada pada sistem, lalu mengamati respon di smartphone apakah dapat menerima atau tidak notifikasi pop-up ketika dalam keadaan lock screen dan sedang membuka aplikasi lain. Adapun Gambar 14 adalah contoh tampilan notifikasi pop-up ketika smartphone pada keadaan lock screen.

Tabel 6 adalah data hasil pengujian notifikasi pop-up status waspada area depan rumah. Tabel 7 adalah data hasil pengujian notifikasi pop-up status waspada area samping rumah. Data hasil pengujian notifikasi pop-up status bahaya pintu depan rumah dapat dilihat pada Tabel 8. Pada Tabel 9 diperoleh data hasil pengujian notifikasi pop-up status bahaya pintu samping rumah. Data hasil pengujian notifikasi pop-up ketika kondisi smartphone pada keadaan sedang membuka aplikasi Instagram dapat dilihat pada Tabel 10.

Tabel 6. Notifikasi pop-up status waspada area depan rumah

\begin{tabular}{|c|c|c|c|}
\hline No & Android & Notifikasi Pop-up & Delay \\
\hline 1 & Lock Screen & Aktif & 1 detik \\
\hline 2 & Lock Screen & Aktif & 2 detik \\
\hline 3 & Lock Screen & Aktif & 1 detik \\
\hline 4 & Lock Screen & Aktif & 1 detik \\
\hline 5 & Lock Screen & Aktif & 2 detik \\
\hline 6 & Lock Screen & Aktif & 2 detik \\
\hline 7 & Lock Screen & Aktif & 1 detik \\
\hline 8 & Lock Screen & Aktif & 1 detik \\
\hline 9 & Lock Screen & Aktif & 1 detik \\
\hline 10 & Lock Screen & Aktif & 2 detik \\
\hline
\end{tabular}




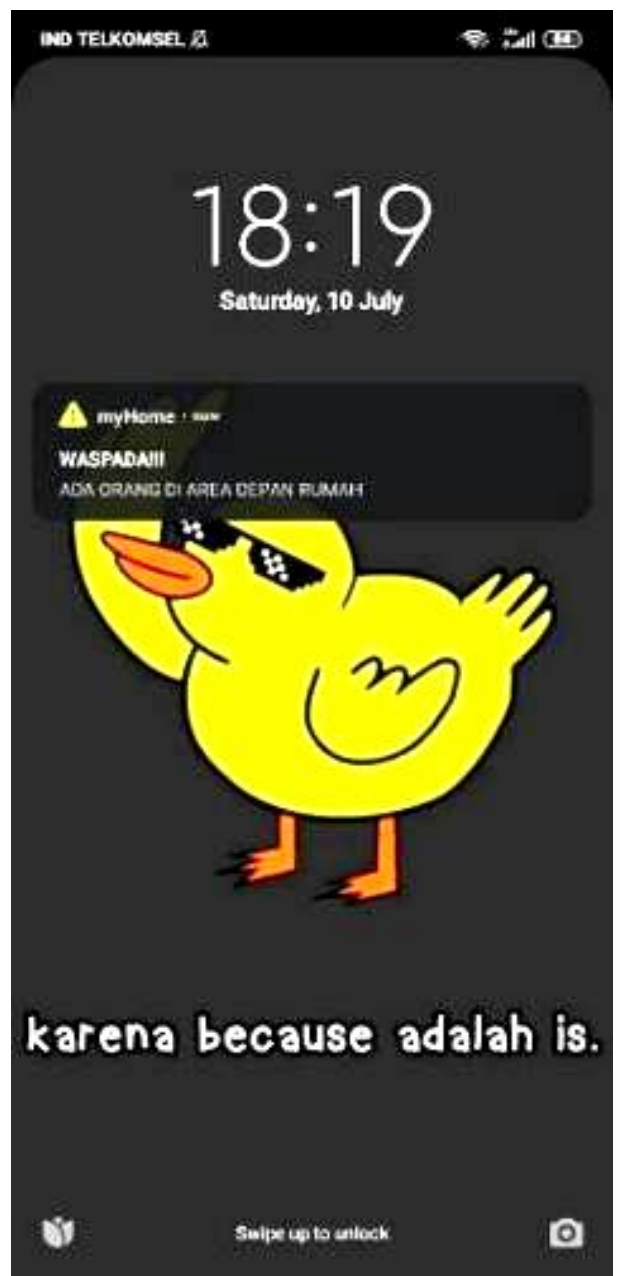

Gambar 14. Pop-up Notifikasi Saat Android Lock Screen

Dari hasil Tabel 6 sistem membutuhkan waktu delay 1 sampai 2 detik untuk dapat mengirimkan notifikasi pop-up ketika smartphone dalam keadaan lock screen.

Tabel 7. Notifikasi pop-up status waspada area samping rumah

\begin{tabular}{|c|c|c|c|}
\hline No & Android & Notifikasi Pop-up & Delay \\
\hline 1 & Lock Screen & Aktif & 2 detik \\
\hline 2 & Lock Screen & Aktif & 2 detik \\
\hline 3 & Lock Screen & Aktif & 2 detik \\
\hline 4 & Lock Screen & Aktif & 2 detik \\
\hline 5 & Lock Screen & Aktif & 1 detik \\
\hline 6 & Lock Screen & Aktif & 1 detik \\
\hline 7 & Lock Screen & Aktif & 2 detik \\
\hline 8 & Lock Screen & Aktif & 1 detik \\
\hline 9 & Lock Screen & Aktif & 1 detik \\
\hline 10 & Lock Screen & Aktif & 3 detik \\
\hline
\end{tabular}

Dari hasil Tabel 7 sistem membutuhkan waktu delay 1 sampai 3 detik untuk dapat mengirimkan notifikasi pop-up status waspada area samping rumah ketika smartphone dalam keadaan lock screen. 
Tabel 8. Notifikasi pop-up status bahaya pintu depan rumah

\begin{tabular}{|c|c|c|c|}
\hline No & Android & Notifikasi Pop-up & Delay \\
\hline 1 & Lock Screen & Aktif & 1 detik \\
\hline 2 & Lock Screen & Aktif & 2 detik \\
\hline 3 & Lock Screen & Aktif & 2 detik \\
\hline 4 & Lock Screen & Aktif & 3 detik \\
\hline 5 & Lock Screen & Aktif & 2 detik \\
\hline 6 & Lock Screen & Aktif & 1 detik \\
\hline 7 & Lock Screen & Aktif & 2 detik \\
\hline 8 & Lock Screen & Aktif & 2 detik \\
\hline 9 & Lock Screen & Aktif & 1 detik \\
\hline 10 & Lock Screen & Aktif & 3 detik \\
\hline
\end{tabular}

Dari hasil Tabel 8 sistem membutuhkan waktu delay 1 sampai 3 detik untuk dapat mengirimkan notifikasi pop-up status bahaya ketika smartphone dalam keadaan lock screen.

Tabel 9. Notifikasi pop-up status bahaya pintu samping rumah

\begin{tabular}{|c|c|c|c|}
\hline No & Android & Notifikasi Pop-up & Delay \\
\hline 1 & Lock Screen & Aktif & 2 detik \\
\hline 2 & Lock Screen & Aktif & 2 detik \\
\hline 3 & Lock Screen & Aktif & 1 detik \\
\hline 4 & Lock Screen & Aktif & 1 detik \\
\hline 5 & Lock Screen & Aktif & 3 detik \\
\hline 6 & Lock Screen & Aktif & 2 detik \\
\hline 7 & Lock Screen & Aktif & 1 detik \\
\hline 8 & Lock Screen & Aktif & 1 detik \\
\hline 9 & Lock Screen & Aktif & 3 detik \\
\hline 10 & Lock Screen & Aktif & 3 detik \\
\hline
\end{tabular}

Dari hasil Tabel 9 sistem membutuhkan waktu delay 1 sampai 3 detik untuk dapat mengirimkan notifikasi pop-up status bahaya pintu samping rumah ketika Android dalam keadaan lock screen.

Tabel 10. Notifikasi pop-up Android ketika membuka aplikasi lain

\begin{tabular}{|c|c|c|c|}
\hline No & Android & Notifikasi Pop-up & Delay \\
\hline 1 & Membuka Instagram & Aktif & 1 detik \\
\hline 2 & Membuka Instagram & Aktif & 1 detik \\
\hline 3 & Membuka Instagram & Aktif & 1 detik \\
\hline 4 & Membuka Instagram & Aktif & 2 detik \\
\hline 5 & Membuka Instagram & Aktif & 2 detik \\
\hline 6 & Membuka Instagram & Aktif & 2 detik \\
\hline 7 & Membuka Instagram & Aktif & 1 detik \\
\hline 8 & Membuka Instagram & Aktif & 1 detik \\
\hline 9 & Membuka Instagram & Aktif & 2 detik \\
\hline 10 & Membuka Instagram & Aktif & 1 detik \\
\hline
\end{tabular}

Dari hasil Tabel 10 sistem membutuhkan waktu delay 1 sampai 2 detik untuk dapat mengirimkan notifikasi pop-up ketika smartphone sedang membuka aplikasi Instagram. 


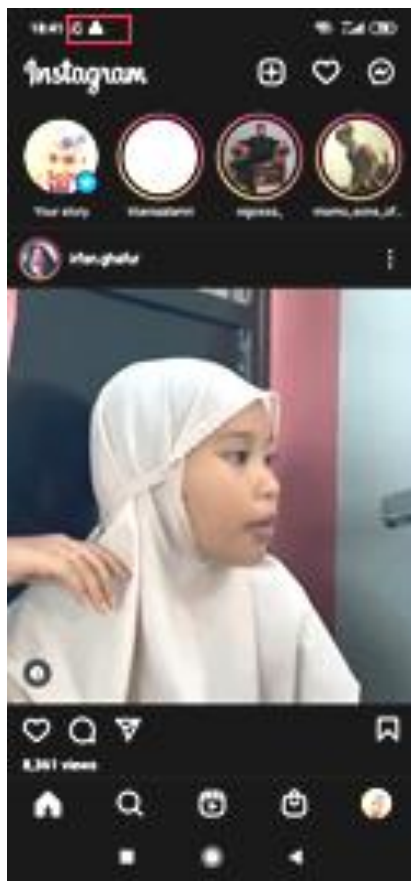

Gambar 15. Smartphone sedang membuka Instagram

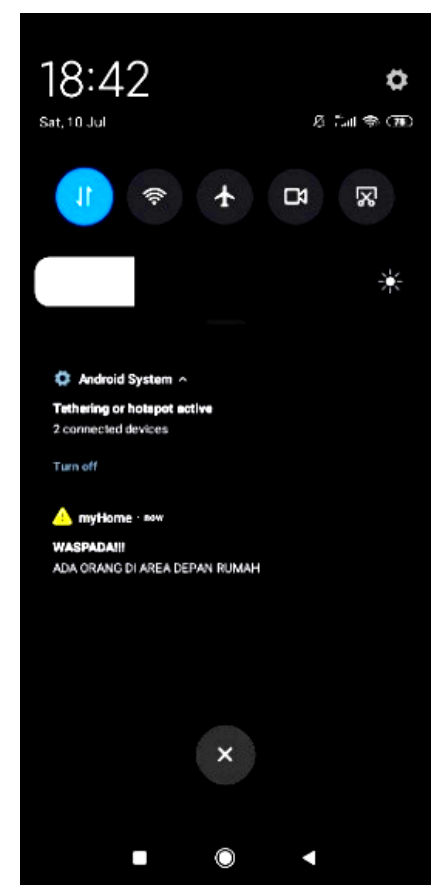

Gambar 16. Pop-up notifikasi masuk

Gambar 15 memperlihatkan tampilan sebuah smartphone yang sedang membuka aplikasi Instagram dapat diinterupsi oleh notifikasi pop-up bila sistem mengirimkan status waspada seperti terlihat pada Gambar 16.

\section{Kesimpulan}

Setelah merealisasikan perancangan serta pengujian sistem keamanan rumah ini didapatkan beberapa kesimpulan. Status waspada aktif jika sensor HC-SR501 pada depan rumah dan sensor HC-SR501 pada samping rumah mendeteksi pergerakan manusia dengan jarak maksimum sejauh 5 meter dengan waktu delay 2 sampai 4 detik. Status bahaya akan aktif jika sensor MC-38 pada pintu depan rumah aktif dan sensor MC- 38 pada pintu samping rumah aktif dengan waktu delay 1 sampai 3 detik. Pop-up notifikasi akan aktif ketika sistem mendeteksi status waspada dan bahaya ketika Android sedang dalam keadaan lock screen dengan waktu pengiriman notifikasi sebesar 1 sampai 3 detik. Pop-up notifikasi aktif ketika Android sedang membuka aplikasi Instagram dengan waktu pengiriman notifikasi sebesar 1 sampai 2 detik.

\section{Saran}

Untuk meningkatkan efisiensi dan fungsi pada sistem keamanan rumah ini, ada beberapa pengembangan yang dapat dilakukan:

1. Membuat sistem menjadi multi-jaringan intenet (WiFi), sehingga ketika WiFi sewaktu-waktu terputus, maka sistem memiliki jaringan internet lain sebagai back up.

2. Membuat catu daya cadangan seperti baterai jika sewaktu-waktu aliran listrik di rumah mati atau sengaja dimatikan oleh pencuri. 
3. Menambahkan aktuator keamanan ketika sistem mendeteksi status waspada atau status bahaya, dikarenakan sistem ini hanya memiliki indikator peringatan.

\section{Daftar Pustaka}

[1] CNN Indonesia, "Kriminalitas di Jakarta Meningkat 10 Persen Selama Corona," CNN Indonesia. [Online]. Available: https://www.cnnindonesia.com/nasional/ 20200427163324-12-497753/ krimi nalitas-di-jakarta-meningkat-10-persen-selamacorona. [Accessed: 02-Jan-2021].

[2] PRF News, "Pencurian Rumah Kosong Domonasi Kota Bandung," PRF News. [Online]. Available: https://prfmnews.pikiran-rakyat.com/bandung-raya/ pr131196120/pencurian-rumah-kosong-dominasi-angka-kriminalitas-di-kotabandung-sepanjang-2020. [Accessed: 02-Jan-2021].

[3] R. Khana and dkk, "Rancang Bangun Sistem Keamanan Rumah Berbasis Internet of Things Dengan Platform Android," J. Kaji. Tek. Elektro, vol. 3, no. 1, 2018.

[4] D. Setiawan and dkk, "Perancangan Sistem Pengontrol Keamanan Rumah dengan Smart CCTV Menggunakan Arduino Berbasis Telegram," J. Nas. Inform. dan Teknol. Jar., vol. 4, no. 1, 2019.

[5] J. Irianto and dkk, "Rancang Bangun Sistem Keamanan Rumah Menggunakan Sensor PIR Berbasis Raspberry PI," J. Comput. Sci. vol2, no. 1, Univ. Muhammadiyah, 2020.

[6] M. S. Sungkar, "Sistem Keamanan Rumah Berbasis Internet of Thing," Smart Comp, vol. 9, no. 2, 2020.

[7] E. A. Zaki and dkk, "Prototipe Sistem Keamanan Rumah Berbasis Web dan SMS Gatewa," J. Telekomun. Elektron. Komputasi dan Kontrol, vol. 6, no. 1, 2020.

[8] Datasheet, “WeMos D1 Mini," Datasheet. [Online]. Available: https://www.wemos.cc/en/latest/d1/d1mini.html. [Accessed: 12-Jan-2021].

[9] Datasheet, "HC-SR501 PIR Sensor," Datasheet. [Online]. Available: https://datasheetspdf.com/pdf-file/775434/ETC/HC-SR501/1. [Accessed: 10- Jan-2021].

[10]Datasheet, “MC-38 Door Switch," Datasheet. [Online]. Available: http://synacorp.my/v3/en/arduino-sensors/143 -mc-38-door-window-magneticsensor-switch-for-arduino-iot-alarm-system.html. [Accessed: 12-Jan-2021]. 